\title{
Desafios para Moçambique na Implementação de Políticas de Sustentabilidade Verde-azul
}

\section{Reginaldo Ernesto Nhachengo}

Assistente estagiário na Universidade Joaquim Chissano (UJC), Departamento de Administração Pública. Doutorando em Políticas Públicas e Formação Humana na Universidade do Estado do Rio de Janeiro (PPFH/UERJ). renhafiel@gmail.com

\section{Resumo}

A degradação ambiental resulta da tendência de maximização dos ganhos econômicos em detrimento dos ecológicos, dando origem à distorção funcional dos ecossistemas e pondo em risco a vida. Para reverter este cenário foi proposta uma abordagem de desenvolvimento sustentável baseada em vários modelos normativos. Com base na revisão da literatura, o artigo analisa a essência das políticas no âmbito dos paradigmas de desenvolvimento verde-azul, por forma a contribuir para a visualização de instrumentos inovativos de formas de produção e consumo capazes de maximizar os ganhos socioeconômicos e ecológicos à escala global. O estudo constata algumas fragilidades em ambos paradigmas e elenca alguns desafios para Moçambique, em particular, implementar políticas com mais probabilidade de alcançar a sustentabilidade. Palavras-chave: paradigma azul, paradigma verde, políticas, desenvolvimento sustentável.

\section{Challenges for Mozambique in implementing the green-blue policies for sustainability}

\section{Abstract}

Environmental degradation results from the paradox between the tendency to maximize economic advantages instead of ecological ones, giving rise to the functional distortion of ecosystems and putting life at risk. To reverse this scenario, a sustainable development approach, based on several normative models, was proposed. Based on the literature review, the article analyzes the essence of policies within the framework of greenblue development paradigms, in order to contribute to the visualization of innovative instruments of forms of production and consumption capable of maximizing global socioeconomic and ecological gains. The study finds some weaknesses in both paradigms

1 Desde a Revolução Industrial os oceanos absorveram cerca de 25\% do CO2 antropogênico, resultando em 26\% da acidificação dos oceanos. À medida que a acidificação aumenta, reduz a capacidade dos oceanos de absorver o $\mathrm{CO} 2$ da atmosfera, reduzindo igualmente sua capacidade de regular o clima. 
and lists some challenges for Mozambique, in particular, to implement policies most likely to achieve sustainability.

Keywords: blue paradigm, green paradigm, policies, sustainable development.

\section{Desafíos para Mozambique en la implementación de políticas de sustentabilidad verde-azul}

\section{Resumen}

La degradación ambiental resulta de la tendencia a maximizar las ganancias económicas en detrimento de las ecológicas, dando lugar a la distorsión funcional de los ecosistemas y poniendo en riesgo la vida. Para revertir este escenario, se propuso un enfoque de desarrollo sustentable basado en varios modelos normativos. Con base en la revisión de la literatura, el artículo analiza la esencia de las políticas en el marco de los paradigmas de desarrollo verde-azul, con el fin de contribuir a la visualización de herramientas innovadoras de formas de producción y consumo capaces de maximizar las ganancias socioeconómicas y ecológicas a escala global. El estudio encuentra algunas debilidades en ambos paradigmas y enumera algunos desafíos para Mozambique, en particular, para implementar políticas con más probabilidades de lograr la sustentabilidad.

Palabras-chave: paradigma azul, paradigma verde, políticas, desarrollo sustentable.

\section{Introdução}

Atualmente o homem vive num mundo com sérios problemas ecológicos e sociais. A poluição, e a consequente acidificação e aquecimento global, é o resultado manifesto da atitude humana face à natureza. Essa atitude, que está na gênese do problema, centra-se num desenvolvimento paradoxal da maximização dos ganhos econômicos e minimização dos ecológicos, resultando na distorção funcional e redução da capacidade reprodutiva dos ecossistemas até à extinção de espécies. A pobreza que os governos tentam erradicar, sobretudo nos países da periferia, também se integra neste paradoxo de desenvolvimento. Muitos países, à símile de Moçambique, não conseguem promover um desenvolvimento econômico equilibrado. As atividades econômicas levadas a cabo pelas respetivas populações lesam por demais os ecossistemas. A título de exemplo, a exploração mineira artesanal nas províncias de Manica, Zambézia e Cabo Delgado (garimpo) não só lesa o sistema social como também o natural. Portanto, o desenvolvimento é abordado na mesma lógica antagônica: win-lose.

A Avaliação Ecossistêmica do Milênio (MEA) destaca que, nos últimos 50 anos, danificaram-se os ecossistemas mais rápida e extensivamente que em qualquer outro intervalo de tempo equivalente na história da humanidade (MEA, 2005). O resultado dessa ação humana foi a degradação, em pelo menos 60\%, de serviços ecossistêmicos úteis para o bem-estar humano, embora tenha havido alguns ganhos econômicos. Existe um credo de que o declínio da saúde ecológica e da produtividade econômica pode ser revertido ao mudar para um paradigma econômico mais ecológico e sustentável, no qual o bem-estar humano e a equidade social sejam melhorados, enquanto os riscos ambientais e 
as escassezes ecológicas são reduzidas (UNEP et al., 2012, p. 6). De fato, com o intuito de reverter o cenário de desenvolvimento antagônico surgiram ideias, sobretudo na década de 1970, que orientam os países a enveredar por políticas que promovem um desenvolvimento ecológico - paradigma verde - e, recentemente, novas ideias são supletivamente avançadas para reforçar este paradigma, na expectativa de inventar ciclos virtuosos de uso e reuso dos recursos localmente disponíveis - paradigma azul -, haja vista criar mais empregos às comunidades e reduzindo desta forma a pobreza a longo termo.

Este trabalho faz uma abordagem sobre os dois principais paradigmas de desenvolvimento sustentável, analisando a essência das políticas de cada paradigma e apresentando alguns desafios para Moçambique, haja vista contribuir para a concretização do ideal de sustentabilidade. Ao longo do debate encara-se o paradigma azul como um modelo de desenvolvimento que, com o mesmo espírito de promover a sustentabilidade, complementa o modelo verde em curso a nível global. A primeira parte do artigo resume o ideal de desenvolvimento sustentável; a segunda capta a essência do paradigma de desenvolvimento verde, incluindo as principais políticas e críticas; a terceira parte apresenta a visão holística do paradigma de desenvolvimento azul e suas políticas. Apresenta-se, na última parte, alguns desafios para Moçambique no contexto dessas políticas de desenvolvimento sustentável.

\section{O ideal de sustentabilidade: gênese e consensos}

Os problemas ambientais não surgem apenas como resultado de aplicação de novas tecnologias. A tecnologia é um trampolim que pode, inclusive, assegurar a saúde ecológica. A descoberta da tecnologia do fogo na pré-história (a sua generalização se deu por volta de 300.000 a. C.), por exemplo, marcou uma revolução civilizacional. Com ela, a relação homem-natureza mudou, porque aquele já podia controlar o fogo em seu benefício, pese embora afetando alguns sistemas bióticos e abióticos. A mudança drástica na relação homem-natureza que vem resultando no desequilíbrio ecológico, nesse sentido, é especialmente corolário da atitude humana que tende a recorrendo a métodos de produção e consumo ecologicamente nocivos. Historicamente, o problema emerge sobretudo no século XVIII, com a Revolução Industrial, na qual houve mudança de métodos de produção manufatureira para a maquinofatura, aumentando a poluição com a utilização de combustíveis fósseis.

Rogers et al. (2008, p. 109) apresentam três tipos de questões relativas à degradação ambiental: O tipo-I (Brown issues), lida com problemas convencionais de poluição. O tipo-II (Green issues), lida com questões ecológicas mais amplas, como diversidade biológica, conservação de ecossistemas. O tipo-III (Red Issues), lida com instituições, políticas e legislação atinente ao ambiente. Considerando esta tipologia, o principal problema ambiental é a poluição da água e do ar. Os problemas de poluição e a atitude de consumo excessivo, ou seja, exploração dos recursos além da capacidade regenerativa dos ecossistemas, reforçam-se na degradação da natureza e na diminuição da qualidade de vida sobre ela.

A despeito de a degradação ambiental ser longínqua, a preocupação com esta 
problemática teve lugar apenas nos meados do século passado (Rogers et al., 2008; Bittencourt et al., 2012) e se consubstanciou na procura de modelos normativos que assegurassem um desenvolvimento sustentável. Neste período, a solução limitava-se no abate da poluição causada pelos países do Centro. A partir do terceiro quartel do século XX, tiveram lugar, à escala internacional, vários eventos, primeiro, para aprimorar o entendimento do conceito de sustentabilidade e, segundo, harmonizar modelos e ações que o pudessem concretizar (vide gráfico 1). De acordo com Pauli (2011), os primeiros escritos relativos à questão da sustentabilidade surgem nos meados do século $\mathrm{XX}$, com a publicação da obra Deep Ecology, da autoria de Arne Næss, em 1950. Ainda assim, a conferência histórica que discutiu sobre ambiente e desenvolvimento teve lugar em 1972 e culminou com a criação do Programa das Nações Unidas para o Meio Ambiente (PNUMA). A questão central na génese do ideal de sustentabilidade e que, explícita ou implicitamente, tem vindo a orientar todos os eventos deste género é: que desenvolvimento nós queremos ou que futuro nós queremos? Esta questão suscitou debates nos círculos acadêmicos e uma variedade de respostas e modelos instrumentais foi sugerida.

Gráfico 1: Principais eventos relativos à sustentabilidade

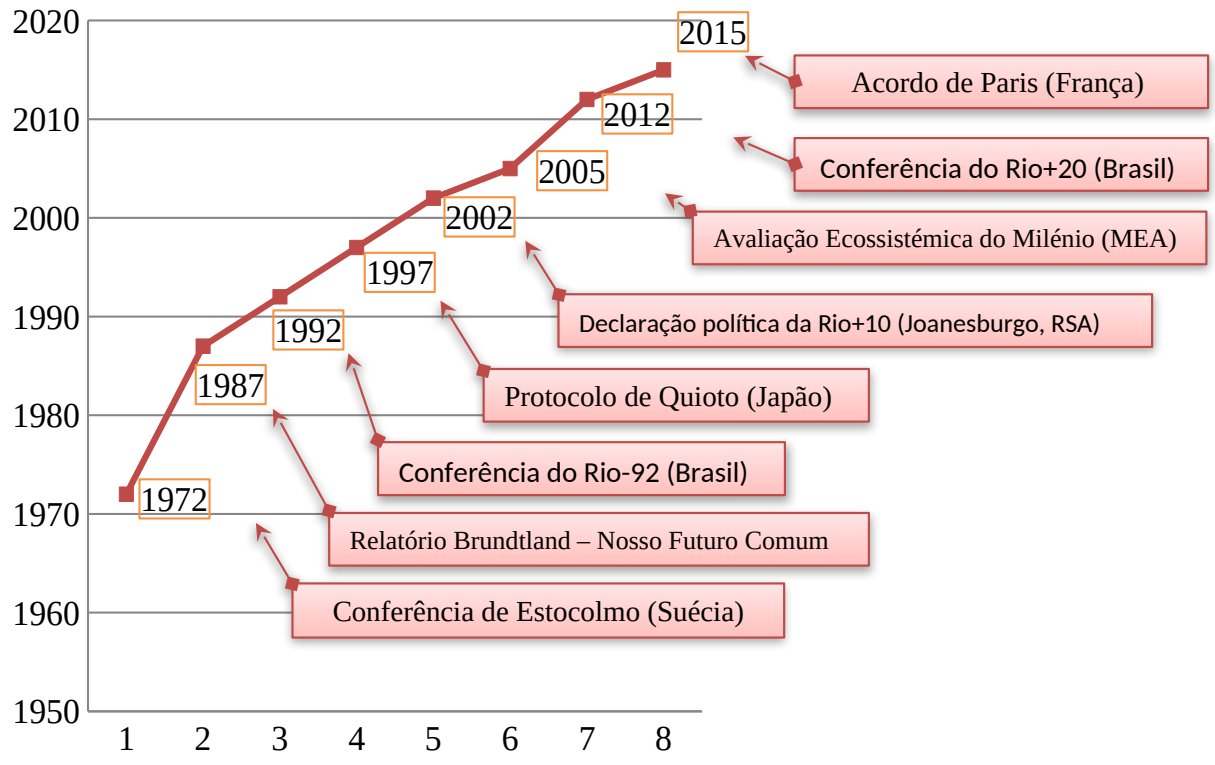

Quem deu pela primeira vez a resposta foi a Comissão Mundial sobre Meio Ambiente e Desenvolvimento (CMMAD1)², em 1987, através da publicação do relatório Brundtland, intitulado Nosso Futuro Comum, contendo a primeira definição de desenvolvimento sustentável (Elliott, 2006). Nos termos desta Comissão, o desenvolvimento sustentável é o que permite a "satisfação das necessidades presentes, sem comprometer a capacidade das gerações futuras de satisfazer suas próprias necessidades" (Rogers et al., 2008, p. 23). Este entendimento, embora represente um importante esforço conceitual e continue a ser o mais citado, é incompleto, por se alicerçar numa dimensão (ambiental) e não elucidar o elo entre as duas gerações. A

2 As Nações Unidas estabeleceram, em 1984, um grupo independente de 22 indivíduos para identificar estratégias ambientais para a comunidade internacional (Elliott, 2006, p. 7). 
lacuna resultou numa inércia em termos de ações efetivas para alcançar aquele ideal, por isso, o conceito foi aprimorado. Nos anos de 1990, por exemplo, havia cerca de 70 definições do mesmo conceito (Elliott, 2006, p. 9), evidenciando o dissenso e a variedade de modelos normativos.

O grande compromisso à causa da sustentabilidade surge da Conferência do Rio1992 sobre ambiente e desenvolvimento, que aprovou a "Agenda 21", com indicações relativas a problemas ambientais e econômicos, conservação e gestão de recursos. Os princípios 3, 4 e 5 desta declaração focam, respectivamente, na necessidade de promover ações que estimulem o desenvolvimento social e ambiental para o bem-estar de ambas as gerações; na necessidade de integrar as questões de proteção ambiental nos processos de desenvolvimento; e na necessidade de cooperação de todos na missão essencial de erradicação da pobreza (UN, 1992). Como se percebe, o foco da dimensão ambiental alarga-se para a dimensão social, incluindo questões como pobreza e população. A CMMAD adopta então um plano de ação para o século XXI - Agenda 21 - focando no ambiente e desenvolvimento.

Segundo Rogers et al. (2008, p. 24), em 1993, Mohan Munasinghe tinha já discutido três abordagens do desenvolvimento sustentável: a abordagem econômica, ecológica e sociocultural. Mas o entendimento consensual brotaria da Rio +10 , em 2002, quando a Cúpula reunida em Joanesburgo entende que "o desafio da sustentabilidade passa por contemplar a interdependência de três dimensões de desenvolvimento: ambiental, social e econômica" (Elliott, 2006, p. 9). A sustentabilidade pressupõe, pois, uma conciliação das três dimensões, convergindo sempre na melhoria da qualidade de vida de todos, e não apenas dos humanos. A busca de um equilíbrio que procura a maximização de ganhos econômicos, ecológicos e sociais - ganhos comumente designados de soluções do tipo win-win - é que caracteriza a sustentabilidade. Aliás, este é o ideal que os países e governos, desde os anos de 1950, têm procurado alcançar. A maior parte das políticas implementadas, senão todas, como seja a Agenda 21, Agenda 2000-2015/ ODM, Agenda 2015-2030/ODS e os paradigmas de desenvolvimento verde-azul, intentam tornar factível esta aspiração global, que pode ser descrita como a bússola das práticas da humanidade rumo a sustentabilidade. Este trabalho analisa, a seguir, os dois principais paradigmas de sustentabilidade: o verde e o azul.

\section{O paradigma de desenvolvimento verde}

O debate em torno dos problemas ecológicos, como se viu, teve como corolário a assunção de paradigmas de desenvolvimento sustentável, ou seja, conjunto de assunções normativas sobre como o mundo pode promover o desenvolvimento equilibrado, num dado momento histórico. O paradigma verde marca a transição do velho paradigma de economia marron (brown economy) considerado ineficiente. Como indica a Climate Transparency (2016, p. 5) no seu relatório Brown to Green, a ideia por detrás do paradigma verde é permitir um recuo nas práticas que destroem o clima - e toda a cadeia de

3 A conferência de Joanesburgo termina com a assinatura de uma declaração política de compromisso para alcançar a sustentabilidade, através de planos de ação para a redução da pobreza, mudança de padrões insustentáveis de produção e de consumo, protegendo e gerindo a base de recursos naturais (Elliott, 2006). 
ecossistemas -, através da queima de combustíveis fósseis e transitar para uma economia verde, de baixo carbono. As políticas que sustentaram essa transição mostraram-se eficazes na criação da riqueza e altos índices do PIB (Patil et al., 2016, p. 43; OECD, 2011). Só para citar alguns exemplos, as experiências mundiais de sucesso incluem o planejamento urbano no Brasil, agricultura orgânica no Uganda, infra-estruturas verdes nas zonas rurais da Índia. Para concretizar a transição, os países assumiram vários compromissos, sendo de destacar a Agenda 21 da Rio-92; o Protocolo de Quioto de $1997^{4}$ sobre mudanças climáticas; Declaração da Rio+20 - The future we want - focando na questão do alargamento do conceito de economia verde e a reafirmação da erradicação da pobreza (UN, 2012, p. 9), e o recente Acordo de Paris de 2015, que insta o G20 a limitar as emissões (Climate Transparency, 2016).

Por quê se precisa da economia verde e o que vem a ser? A primeira questão identifica a razão de ser do paradigma verde. A economia verde tem em vista contribuir para a erradicação da pobreza bem como suster o crescimento econômico, aumentando as oportunidades de inclusão social, melhorando o bem-estar social e mantendo um funcionamento salutar dos ecossistemas terrestres (UN, 2012). Noutra faceta, justifica-se pelo fato de os riscos ao desenvolvimento aumentarem à medida que as atuais abordagens de desenvolvimento corroem o capital natural ${ }^{5}$, o que, se não for revertido, resultará na escassez de água potável em 33\% até 2025; aumento da poluição ${ }^{6}$ e consequentes mudanças climáticas; perda da biodiversidade em pelo menos 10\% até 2030; e, de um modo geral, periga as possibilidades de crescimento e existência no futuro (OECD, 2011, p. 4).

A segunda questão incide sobre a essência do paradigma verde. $\mathrm{O}$ conceito vem sendo discutido desde 1989, mas foi lançado oficialmente em 2008 pelo PNUMA (Bittencourt et al., 2012). A economia verde significa impulsionar o crescimento econômico e desenvolvimento, enquanto isso garantindo que os ativos naturais continuem a prover os recursos e serviços ambientais sobre que reside o bem-estar (OECD, 2011, p. 4). Trata-se de uma abordagem de desenvolvimento apoiada em três estratégias principais: a redução das emissões de carbono, uma maior eficiência energética no uso de recursos e a prevenção da perda da biodiversidade e dos serviços ecossistêmicos. Esta visão, portanto, está embasada na conciliação entre o problema econômico e o ambiental, no sentido de se obter políticas que incidam sobre "o crescimento econômico sem a redução do capital natural agregado e sua ligação com a redução da pobreza" (Patil et al., 2016, p. 42). No geral, o paradigma verde é parte da aspiração global sobre a sustentabilidade e tem em vista oferecer alternativas de ação que ajudem a alcançar esse ideal, pelo menos nas facetas da dimensão econômica e ambiental, que são o cerne do conceito, recorrendo, por exemplo, a estratégias de uso eficiente da energia, de redução das emissões de carbono de efeito estufa e de conservação de ecossistemas.

No complexo de questões ambientais apresentadas por Rogers et al. (2008), o paradigma de desenvolvimento verde procura contrapor os problemas de sustentabilidade

4 O Protocolo de Quioto desafiou os países industrializados a reduzirem, até 2012, emissões de gases do efeito estufa, adotando os Mecanismos de Desenvolvimento Limpo e Redução Certificada de Emissões.

$5 \mathrm{O}$ capital natural integra a globalidade geológica, solo, ar, água e organismos vivos.

6 O G20 representa $2 / 3$ da população mundial, $85 \%$ da riqueza global e $74.9 \%$ de emissões de efeito estufa. De 1990 a 2013, as emissões no G20 cresceram em 56\% (Climate Transparency, 2016). 
do Tipo I e II, resultando em políticas de produção e consumo tendentes a reduzir as práticas que lesam os ecossistemas no seu todo. As políticas implementadas no âmbito deste paradigma fazem parte da concretização daquilo que Brown $\left(2009^{7}\right)$ chamou de «Plano B», um plano que visa a salvação da humanidade da situação caótica universal face à problemática ambiental, e que procura estabilizar o clima com "a evolução na eficiência energética, revolução na tecnologia da iluminação, adopção de ferramentas energeticamente eficientes, construção de prédios carbono zero, adopção de transporte eléctrico, economia de novos materiais, [...] entre muitas outras soluções" (Bittencourt et al., 2012, p. 792).

Disto decorre, pois, que as iniciativas consideradas necessárias para a economia verde são numerosas e perpassam várias áreas. Todavia, Burkart (2009) destaca seis setores: energia, transporte, água, resíduos, gestão do solo e construção. Vários países implementam estes kits de iniciativas, embora em níveis bem distintos, em razão da vontade política e possibilidades reais de cada país. Experiências notáveis citadas pela $\operatorname{OECD}(2011$, p. 12-13) incluem, a título ilustrativo, a geração de 17\% de energia eléctrica a partir de fontes renováveis em 2010 (Alemanha), investimento de 3 bilhões de GBP em projetos de baixo teor de carbono em 2012 (Reino Unido), a implementação do transporte limpo reduzindo as taxas de poluição do ar urbano na cidade de Curitiba (Brasil), investimento de 25 bilhões de ZAR na agricultura verde em 2011 (África do Sul). No caso de Moçambique, o paradigma verde é abordado de forma tímida e $a d$-hoc. O instrumento significativo neste âmbito é a Estratégia da Revolução Verde, aprovada em 2007 (GdM, 2007, p. 16-24). A estratégia visa o aumento da produção e produtividade dos pequenos produtores e assenta em 5 pilares, designadamente: (i) Recursos naturais (terra, água, florestas e fauna bravia); (ii) Tecnologias melhoradas; (iii) Mercados e informação atualizada; (iv) Serviços financeiros; e (v) Formação do capital humano e social. A figura 1 resume as principais ações que têm sido implementadas no contexto do paradigma verde a nível global.

No âmbito do paradigma verde, Pauli (2011) destaca duas iniciativas que tiveram, e têm, mais sucesso à escala global, designadamente: a produção limpa e a ecoeficiência. A primeira iniciativa foi desenvolvida sob direção de Jacqueline Aloisi de Larderel e tem em vista a redução dos efeitos da produção industrial sobre o ambiente (poluição). A cleantech baseia-se em tecnologias que minimizam as emissões e a geração de resíduos, através do processo $3 \mathrm{R}$ (reciclar-reparar-reusar), enquanto maximiza as saídas. $\mathrm{O}$ conceito descreve processos produtivos eficientes, que reduzem custos pela utilização de materiais recicláveis. A segunda iniciativa foi desenvolvida pela Business Council for Sustainable Development, sob direção de Hugh Faulkner. A iniciativa visa elevar a produtividade e eficiência produtiva usando pouca matéria bruta da natureza. A ecoeficiência implica gerar mais bens e serviços com menos recursos, ao mesmo tempo que se reduz os desperdícios e poluição nocivos ao ambiente. A iniciativa foi proposta e aceite na Rio-92 como instrumento para efetivar a Agenda 21 (Yadong, 2013). Dentro destas duas abordagens holísticas pode-se incluir as políticas resumidas por Burkart (2009): energias renováveis, construções verdes, transporte limpo, gestão de água,

7 Cf. com o autor citado. 
gestão de resíduos e gestão de solo. Todo este kit visa sobretudo a redução da poluição e aumento da eficiência produtiva (vide figura 1).

Figura 1: Principais iniciativas do paradigma verde
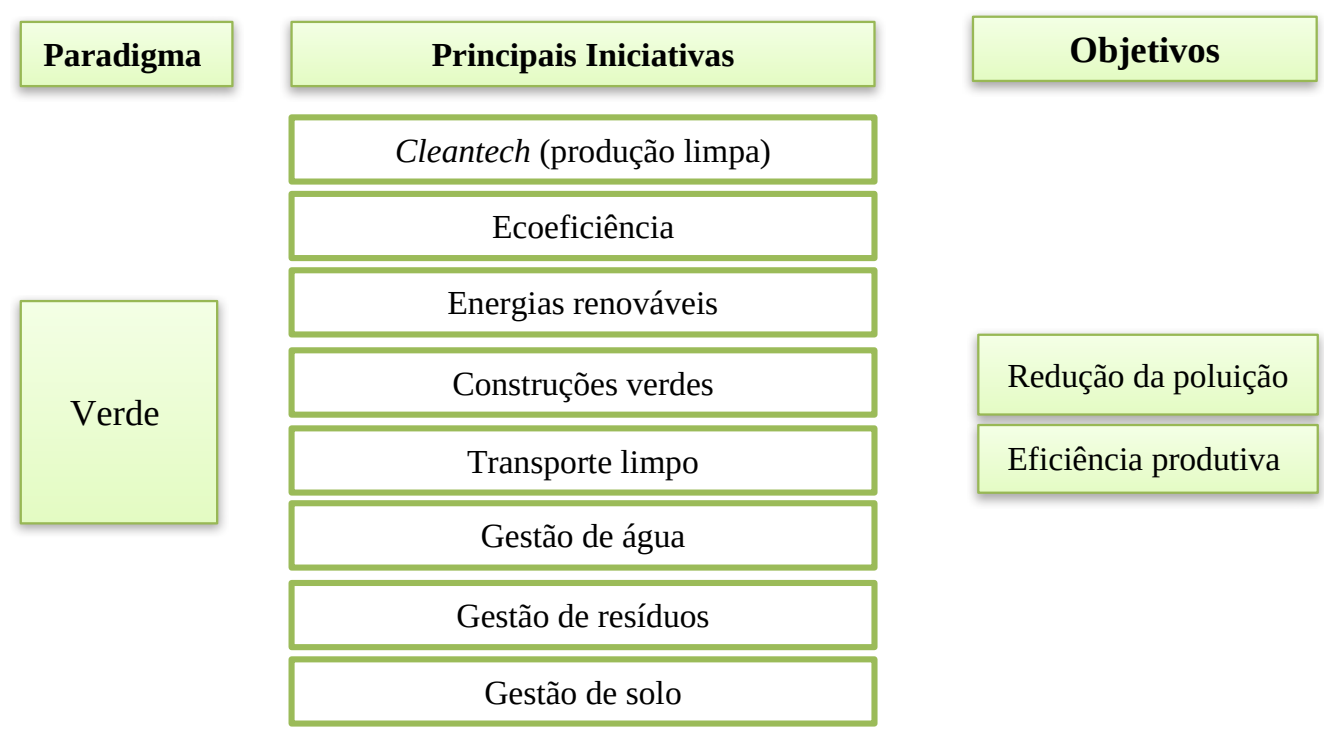

Fonte: Inspirado em Pauli (2011) e Burkart (2009)

As iniciativas visualizadas na figura 1, em geral, dão ênfase na redução dos efeitos que a ação humana impõe sobre a natureza à medida que aumenta suas atividades produtivas, através da harmonização de ganhos econômicos e ecológicos. $\mathrm{O}$ desempenho das políticas aqui discriminadas é mensurado por vários indicadores. Por exemplo, o Índice Global da Economia Verde (GGEI), que mede o desempenho de 80 países e 50 cidades do mundo em termos de progressos rumo à economia verde, usa indicadores agrupados em 4 dimensões: (i) liderança e mudanças climáticas, (ii) mercados e investimentos, (iii) meio ambiente, e (iv) setores de eficiência (GGEI, 2016). Em termos gerais, a medida do sucesso do modelo verde tem incluído o aumento do PIB juntamente com as medidas da manutenção do capital natural, em razão da ênfase nas dimensões econômica e ambiental.

As ideias em torno do paradigma verde baseiam-se no pressuposto de que reduzindo a poluição que o homem impõe à natureza e tornando mais eficiente o processo produtivo resolver-se-ia a crise ambiental. Várias iniciativas foram implementadas sob umbrela deste credo. O problema, contudo, é que desde os meados do século XX iniciativas neste sentido são implementadas e parece não estarem a surtir os efeitos desejados, o que demanda mudança ou pelo menos aprimoramento do paradigma. A MEA (2005) concluiu, por exemplo, que 60\% dos serviços ambientais estão degradados. Por paradoxo, isto acontece precisamente nos últimos 60 anos, período em que as iniciativas têm vindo a serem levadas a cabo. Ademais, o relatório da Climate Transparency revela que "as emissões de gases de efeito estufa não estão a decrescer". A causa primeira disso é que "todos os países do G20 subsidiam suas indústrias baseadas 
em combustíveis fósseis”, ou seja, estimulam a economia marron alicerçada no uso intensivo de energias altamente poluentes - o paradoxo da maximização econômica - a despeito de, em 2009, terem-se comprometido a eliminar os subsídios aos combustíveis fósseis (Climate Transparency, 2016, p. 10) e terem assinado o Protocolo de Quioto, que demanda a redução de emissões de gases de efeito estufa. Em 2018 as emissões globais do G20 continuaram a crescer em $1.8 \%$ e pelos mesmos motivos (Ibidem, 2019 , p. 6). O modelo, portanto, pode ser posto em causa não porque seja totalmente ineficaz, mas pelo cumprimento tangencial e/ou incumprimento dos compromissos por parte dos estados para melhorar a saúde ambiental.

Bittencourt et al. (2012, p. 795-799) fazem críticas não em torno da eficácia do paradigma verde, mas da própria utilidade, e citam vários autores cujas críticas são assim resumidas: (1) o conceito de economia verde vem camuflar a questão da sustentabilidade que se encontra em oposição ao atual modo de produção e consumo, mas, no fundo, trata-se de medidas dentro do mesmo paradigma de dominação da natureza; (2) não existe o verde e o não-verde. Os produtos contêm, nas fases de sua produção, elementos tóxicos, danosos à saúde da terra e da sociedade. $\mathrm{O}$ verde é apenas uma etapa do processo, visto que a produção nunca é de todo ecoamigável; (3) a economia verde propõe o mercado verde, que, por sua vez, fomenta a apropriação privada do bem comum como uma solução para a crise do planeta. É um novo capitalismo, com novas formas de expropriação e acumulação de valor. Por exemplo, se a base para a produção verde é a tecnologia, a importação desta tecnologia resulta no escoamento da riqueza nacional para outras economias, aonde estão domiciliadas as corporações de desenvolvimento tecnológico; (4) a apropriação referida consiste no pagamento por serviços ambientais, isto é, criação de um novo mercado, cuja mercadoria são processos e produtos fornecidos pela natureza, como a purificação da água e do ar, a polinização, o fornecimento de insumos para a biotecnologia; e (5) é uníssono que existe uma crise ambiental que demanda estratégias de mudança, sob pena de se negligenciar o futuro dos recursos naturais do planeta. Resta saber se a economia verde é esta estratégia.

Estas apreciações críticas, aliadas a elevados custos associados aos projetos verdes, bem como a aparente ineficiência e ineficácia do modelo, viriam a ser a base para a proposta de outro modelo, assente sobretudo em princípios éticos e também no princípio de endogenicidade. A lógica do novo modelo é que se o verde mostra-se ineficaz e gera mercado verde, ou seja, uma continuidade sútil do capitalismo, com o qual se faz a apropriação dos recursos dos estados, era preciso encontrar uma outra plataforma de referência, que emulasse os processos naturais, permitindo a produção e consumo sem gerar resíduos improdutivos nem poluição, e que aproveitasse recursos localmente disponíveis.

\section{O paradigma de desenvolvimento azul}

"The Blue Economy responds to basic needs of all with what you have, introducing innovations inspired by nature, generating multiple benefits, including jobs and social capital, offering more with less" (Pauli, 1999). 
A generalização do modelo de desenvolvimento verde inspirou muitos países, incluindo Moçambique ${ }^{8}$, a conceber iniciativas consentâneas com a proteção ambiental. $\mathrm{O}$ modelo vem surtindo alguns resultados positivos, embora longe da expectativa. Por exemplo, o Índice Global da Economia Verde, que mede os progressos da economia verde, coloca a Suécia no topo do ranking, seguida pelos outros Nórdicos. Alguns países de África e da América Latina, quais sejam a Zâmbia (8), o Brasil (10), a Costa Rica (11) e Etiópia (14) também tem bons resultados. Mas, países como Moçambique (49 ${ }^{9}$, Mongólia (79), Arábia Saudita (80) ocupam posições altas, revelando problemas de sustentabilidade (GGEI, 2016:11-12). A isto se ajuntam a global degradação massiva do ambiente (MEA, 2005) e o aumento da poluição atmosférica com o aumento das emissões de gases de efeito estufa do G20 (Climate Transparency, 2016; 2019).

Neste sentido, diante da persistência dos problemas no âmbito do paradigma verde, o economista belga, Gunter Pauli, propôs um novo quadro de referência para lidar com a sustentabilidade, dando azo à ação que está na génese da economia azul. Segundo Pauli (2011), a ideia de blue economy surge como corolário dos ideais veiculados desde os meados do século XX, a destacar: natural capitalism, biomimicry, industrial ecology. O economista foi inspirado ainda pelo pensamento da Margulis (1970/1982 $\left.{ }^{10}\right)$ de que "os resíduos provenientes de um reino são matéria noutro reino". Propôs então a "metodologia de cascada de matéria, nutrientes e energia" em que, na mesma lógica das leis de física, sugere o aproveitamento progressivo dos recursos localmente disponíveis e de todos os recursos resultantes dos processos de produção e consumo, à medida que são transformados de um "reino" para o "outro", agregando valor ao longo do processo e criando mais oportunidades de emprego. Assim, Pauli inicia em 1994 uma pesquisa embasada no modelo ético de que não deveria haver lixo ou resíduo (no waste) nem poluição (no emissions), e que tudo deveria ser reutilizado para a geração de valor adicional. Ao contrário do Protocolo de Quioto que sugere a redução de emissões, o fundamento do paradigma azul é ético, pois, nesta perspectiva "ninguém é permitido a furtar pouco, a poluir pouco, a degradar pouco o ambiente", mas que "ninguém deve poluir" (Pauli, 2011).

O entendimento do conceito de economia azul ainda não é consensual, apesar da sua alta aceitabilidade como directriz na formulação de políticas. Ele representa a extensão do velho conceito de economia verde (old green economy), daí que recebe também a designação de nova economia verde (new green economy) ou economia azul (Pauli, 2011). As conferências do Rio+20 e dos SIDS (Small Islands and Developing States) de 2014 levantaram a questão de economia azul e a necessidade de estimular o crescimento azul, particularmente para países insulares com litorais significativos, mas não deixaram claro o que era e na base de que políticas se sustentam (Patil et al.,

$8 \mathrm{O}$ programa 'uma criança uma planta' nas escolas primárias; o uso de painéis solares nas instituições públicas; o reflorestamento das áreas de exploração de madeira; a proibição de plásticos nocivos ao ambiente; são apenas algumas iniciativas no âmbito do paradigma verde em Moçambique.

9 O Índice Global da Economia Verde coloca Moçambique na $5^{\text {a }}$ posição na dimensão Liderança e Mudanças Climáticas, o que implica ter baixa intensidade de carbono; mas prevalecem grandes desafios nas outras três dimensões: $80^{\mathrm{a}}$ e última posição na dimensão Mercados e Investimentos; em torno da $60^{\mathrm{a}}$ posição na dimensão do Meio Ambiente; e em torno da 40a posição na dimensão dos Sectores de Eficiência (GGEI, 2016, p. 46). $10 \mathrm{Cf}$. com a autora citada. 
2016). Há literatura que confunde o conceito de economia azul com o da economia do mar. A confusão decorre do fato de os oceanos serem a cornucópia da humanidade e, portanto, fornecerem alimento, oxigénio e meios de subsistência para todos os sistemas bióticos. Em virtude deste valor do mar, o Economist Intelligence Unit (2015) concebe economia azul, atomisticamente, como "uma economia oceânica sustentável, que emerge quando as atividades econômicas estão em balanço com a capacidade dos ecossistemas oceânicos de suportar, a longo termo, esta atividade e continuar resiliente e saudável".

A WWF (s/d:2) apresenta, no entanto, uma abordagem holística ao enfatizar que o conceito de economia azul "deve respeitar a integridade do ecossistema e que a única via segura para a prosperidade a longo prazo é através do desenvolvimento de uma economia circular”. Em Huxley (2015), economia azul é um modelo inovativo que procura edificar o contexto econômico, ecológico e social, por forma a alcançar o desenvolvimento sustentável. Entende-se, portanto, que a economia azul integra os sistemas ecológicos, que são idealmente aproveitados para promover o crescimento econômico, criando empregos para melhorar a qualidade de vida de todos, isto é, inclusão e equidade social. É esta abordagem holística de economia azul, aqui designado paradigma azul, que este trabalho adota, entendendo-o não simplesmente como uma economia baseada em recursos do e sobre o mar, mas como uma visão global de desenvolvimento alicerçada numa multiplicidade de iniciativas inovadoras de formas de produção e consumo, assentes em economia circular, tendo em vista a concretização do ideal de sustentabilidade.

O paradigma azul não pretende constituir substituto do verde, mas um complemento não mutuamente excludente. Visa oferecer um quadro de referência e uma gama de alternativas operacionais que impulsionem o alcance do mesmo ideal. Aliás, como referem UNEP et al. (2012, p. 7), o objetivo destes modelos é, antes de mais, "criar uma economia verde num mundo azul", ou seja, aquele mundo em que se "melhora o bemestar humano e a equidade social, reduzindo significativamente os riscos ambientais e as escassezes ecológicas" e resultando em empregos sustentáveis, geração de valor econômico duradouro, respeitando o constrangimento dos recursos naturais. Os modelos verde-azul, em razão da sua complementaridade, subscrevem aos mesmos princípios de baixos índices de carbono, uso eficiente de recursos e inclusão social (UNEP et al., 2012). Contudo, o paradigma azul é alicerçado também em princípios éticos para refletir as circunstâncias, necessidades e caraterísticas físico-ecológicas de cada localidade.

O modelo azul, como iniciado por Gunter Pauli, surge como um movimento encarregue de realizar estudos de caso, através da $Z E R I^{11}$ em ação, visando firmar uma nova plataforma para promover a sustentabilidade. A ZERI teve a missão de "implementar casos pioneiros" para demonstrar a viabilidade científica e econômica do novo modelo de produção e consumo (Huxley, 2015, p. 5) Cerca de 3000 casos foram identificados e o foco foi para a inovação que poderia ser empacotada (cluster) em um sistema para funcionar como os ecossistemas naturais, aproveitando inovações desenvolvidas por diversos atores, fazendo uso mais eficiente de todas as forças

11Zero Emissions Research and Initiatives (ZERI) é uma rede global de mentes criativas, sedeada em Suíça, buscando soluções para os problemas do mundo, inspirada nos princípios da natureza. 
infalíveis descritas pela lei da física. Uma das experiências da Fundação ZERI foi a Chido's Blend: um café onde todos os resíduos na fazenda, e no ponto de consumo, são usados para criar alimentos - colocando a cascada entre os reinos em prática (Pauli, 2011). O resultado desses estudos foi compilado em um relatório entregue ao Clube de Roma, um manifesto composto por 21 princípios fundadores declarando um Novo Sistema Econômico de produção ancorado em recursos disponíveis localmente e em sistemas de cascada, no qual o resíduo do processo de produção ou de consumo se torna a matéria-prima para criar um novo fluxo de caixa (Pauli, s/d ${ }^{12}$ ). É a este tipo de iniciativas inspiradas na capacidade dos ecossistemas de aproveitar os recursos pronta e localmente disponíveis, progressivamente transformados e reutilizados, "a fim de aumentar drasticamente a capacidade da humanidade para responder às necessidades básicas de todos" - os Humanos e a Terra-mãe - que consubstanciam o que o relatório ao Clube de Roma intitulou de The blue economy (Pauli, 2011).

Com este círculo virtuoso pode-se mudar o cenário da escassez para a abundância, através de alteração dos atuais processos industriais dependentes de recursos escassos e de alto consumo de energia, para "buscar soluções [locais] baseadas em tecnologias mais simples e mais limpas" (Pauli, s/d), resultando na geração de mais emprego para as comunidades envolvidas, mais crescimento econômico e menos danos à natureza (vide figura 2). A figura visualiza dois sistemas de produção: tradicional e circular. $\mathrm{Na}$ economia tradicional marron ou linear a matéria bruta é obtida da natureza e submetida ao processo produtivo (L1) resultando em bens e serviços e resíduos. Estes resíduos industriais e domésticos, tratando-se da economia linear, cujo ciclo é "fabricar-usardescartar", são diretamente depositados na natureza sob forma de poluição, causando todo o tipo de impactos negativos nos ecossistemas.

Figura 2: Lógica do sistema de cascada ou economia circular

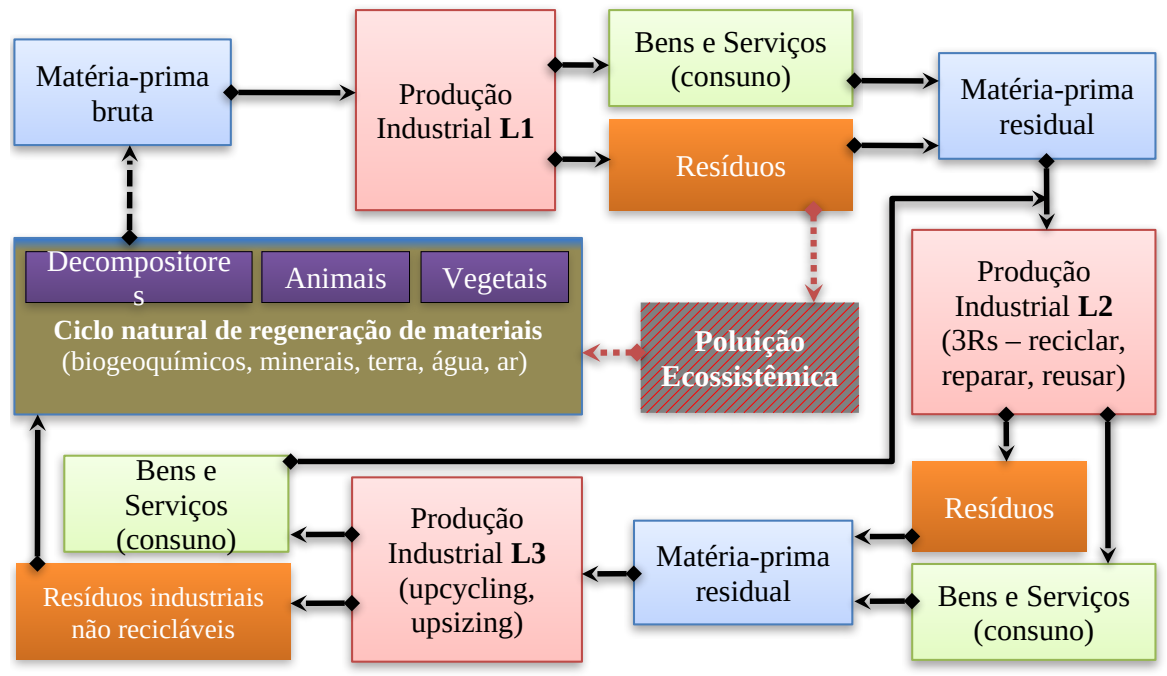

As estratégias de desenvolvimento no âmbito do paradigma verde procuram, como se disse, contrapor sobretudo os problemas decorrentes desta poluição, mas também

12 Cf. com o autor citado. 
aumentar a eficiência produtiva. Na lógica da economia circular ou sistema de cascadas, por outro lado, ocorre uma transformação sistemática e sucessiva do que Pauli (2011) chamou de "matéria, nutrientes e energia" para gerar bens e serviços e regeneração de sistemas naturais. Este processo produtivo não admite grandes desperdícios em virtude de ocorrer um reaproveitamento regular de quase todos os resíduos industriais e domésticos como matéria-prima para um novo ciclo produtivo (L2, L3, etc.), o que resulta numa maior eficiência no uso de recursos localmente disponíveis, viabilizada também pela inovação tecnológica e técnica do clustering de atividades produtivas segundo o fluxo de matéria-prima e energia.

Quando os resíduos, sobretudo industriais, já não podem ser reciclados, quando a sua utilidade marginal no processo produtivo for ínfimo, são reorientados para a regeneração de ativos naturais - como ocorre naturalmente. Ao longo deste processo de produçãoconsumo ocorre não somente o aumento do valor dos recursos, como também se gera grandes oportunidades de emprego, que é uma forma de contribuir para a inclusão social e combate à pobreza. $\mathrm{O}$ mérito do paradigma azul está no reaproveitamento sistemático e quase integral de todos os resíduos gerados, recorrendo ao agrupamento de unidades produtivas em sistemas de cascadas, para viabilizar a emulação do processo natural de regeneração de ecossistemas e conferir alto nível de eficiência produtiva e, no espírito da ZERI, o processo tem de ocorrer sem afetar negativamente a natureza, o que confere altos padrões de sustentabilidade.

De um modo geral, a metodologia de cascada aumenta a eficiência econômica e produtividade, promove o uso de energias azuis, elimina ou reduz drasticamente os resíduos, reduz drasticamente os impactos da produção e do consumo e gera mais oportunidades de equidade e inclusão social. O paradigma azul, neste sentido, constitui um framework que oferece ferramentas práticas e inspiração para o estabelecimento de visões otimistas das possibilidades ilimitadas de desenvolvimento, permitindo a criação de empregos e uma recuperação resiliente das condições de vida, sobretudo em regiões pobres em diversidade de recursos naturais (Huxley, 2015). O paradigma, enquanto plataforma global de desenvolvimento, é alicerçado numa multiplicidade de iniciativas inovadoras de formas de produção e consumo (vide figura 3). 
Figura 3: Principais iniciativas do paradigma azul

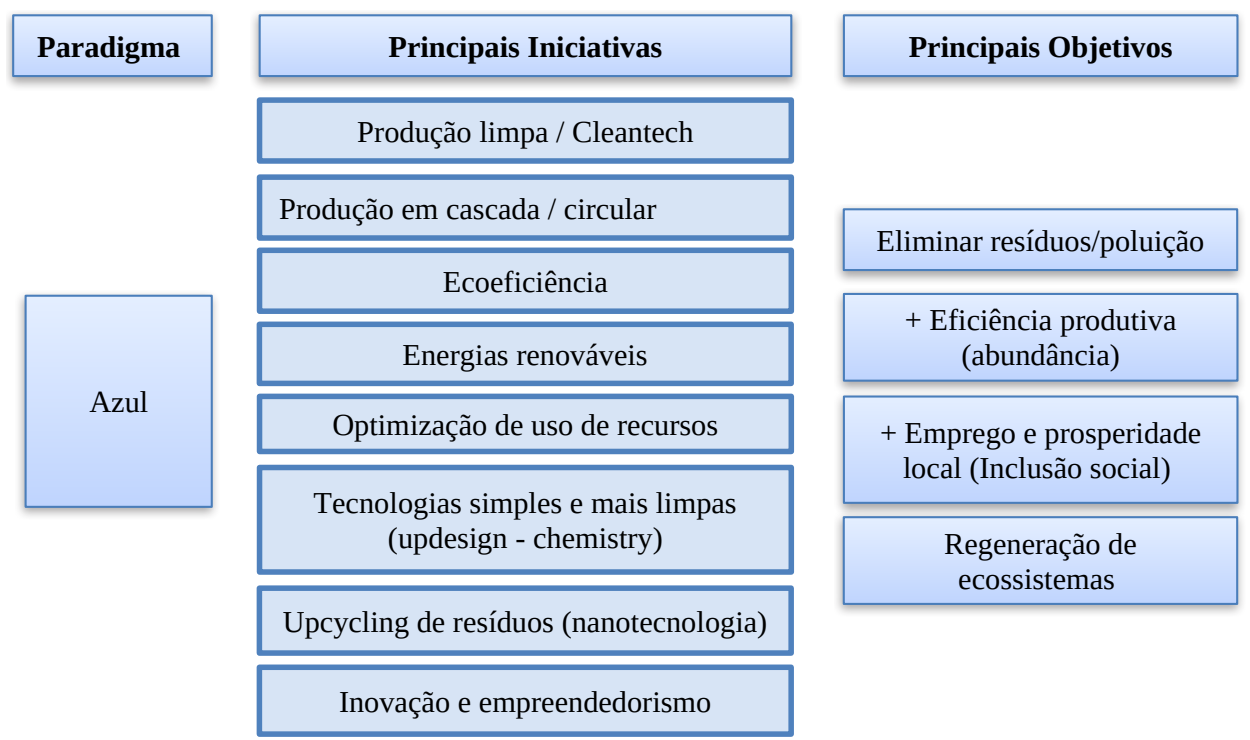

Fonte: Inspirado em Pauli (2011), Huxley (2015) e Walker (2013)

Todas as iniciativas da figura 3 dissociam o desenvolvimento socioeconômico da degradação ambiental, concorrendo para o alcance dos ODS (Objetivos de Desenvolvimento Sustentável). Para conseguir isso, a abordagem de desenvolvimento azul baseia-se na avaliação e incorporação do valor real do capital natural em todos os aspetos da atividade econômica (planejamento, desenvolvimento de infra-estruturas, comércio, viagens, exploração de recursos renováveis, produção de energia/consumo). As estratégias do novo modelo integram: (i) uso de recursos recuperados até esgotar a utilidade produtiva da melhor maneira (inofensiva) e mais barata possível (End-usel Least-cost Approach); (ii) upcycling de resíduos (em oposição a destruição, queima ou dumping); (iii) uso de fontes de energia renováveis (azuis), juntamente com a química verde e nanotecnologia verde para restaurar os ecossistemas, fortificar a economia e gerar mais abundância e prosperidade para todos; e (iv) projeção de sistemas integrados de produção como um todo para oferecer soluções duradouras com múltiplos benefícios (Whole-Systems Design), (Huxley, 2015, p. 4).

Estas características indicam que o paradigma azul é "uma forma de trazer a sustentabilidade [...] para um patamar de objetividade e pragmatismo que evidencia as vantagens econômicas e sociais da aliança entre inovação e melhoria de qualidade ambiental" (Bittencourt et al., 2012, p. 793). Assim, o paradigma azul pode permitir a governos, indivíduos e comunidades locais alcançarem os objetivos do desenvolvimento sustentável (ODS 2015-2030) (UNDP, 2015). Estes objetivos constituem uma espécie de indicadores de sucesso do modelo, visto que analisando os seus 17 atributos, nota-se que uma adopção do paradigma azul pode contribuir para o alcance de pelo menos 10 deles ou mesmo todos. Aliás, como se tem destacado ao longo deste trabalho, ambos paradigmas concorrem vigorosamente para o alcance dessa aspiração de sustentabilidade. 


\section{Desafios para Moçambique face aos paradigmas de desenvolvimento sustentável}

Partindo da tipologia de problemas de sustentabilidade descritos por Roger et al. (2008), esta parte responde ao tipo-III (Red Issues), que lida com políticas, instituições e legislação. Este trabalho não propõe políticas no âmbito das economias verde-azul, apenas apresenta os desafios que os atores envolvidos no processo de desenvolvimento em Moçambique podem considerar nas suas decisões sobre produção e consumo. Considerando a transversalidade das políticas no âmbito dos paradigmas verde-azul, muitos são os desafios que se colocam, e abaixo destacam-se alguns.

\subsection{Apostar na ecoliteracia}

"Education is the most powerful weapon [...] to change the world" (Nelson Mandela).

Um dos grandes desafios para Moçambique tem a ver com a ecoliteracia ou educação ambiental. Governantes e Ambientalistas têm intensificado sensibilizações às comunidades para seu envolvimento massivo nos trabalhos coletivos de saneamento ou sugerem medidas administrativas rígidas (punições, multas, etc.) àqueles que poluem e degradam a natureza. Essas abordagens tradicionais, embora continuem a ser aplicadas, mostram-se pouco eficazes para garantir a saúde dos ecossistemas. Como nota Pauli (2011), “a iniciativa de ecoliteracia é provavelmente a mais crítica de todas. É preciso compreender que a menos que as [comunidades] obtenham literacia em ecossistemas, não há futuro". Neste sentido, a ecoliteracia é o desafio mais importante, porque qualifica os cidadãos para criarem suas iniciativas inspiradas nos ciclos naturais de vida. Uma efetiva educação, formal e não formal, nos domínios do ambiente permitiria às comunidades locais mudar substancialmente sua atitude ou padrões de consumo insustentáveis e, na lógica Gandhiana, permitir que cada indivíduo faça parte ativa da mudança e de desenvolvimento salutar que se vislumbra. O sucesso das políticas de desenvolvimento verde-azul está, portanto, dependente de uma efetiva educação básica sobre como explorar os recursos locais em benefício de todos.

\subsection{Assegurar apoio efetivo às iniciativas de empreendedorismo}

O paradigma azul prevê inovações progressivas e um aproveitamento sucessivo do endowment localmente disponível, incluindo recursos, cultura e tradição. Um dos problemas que aflige os empreendedores é financeiro e de gestão. Neste sentido e com vista a aumentar as possibilidades de sucesso, precisa-se acarinhar as iniciativas locais para contribuir no desenvolvimento nacional. $\mathrm{O}$ apoio efetivo a que se alude pode assumir várias formas, como seja: (i) concessão de subsídios e incentivos fiscais para assegurar o arranque de atividades produtivas, mas também o investimento privado. Em princípio, o apoio deveria ser, como afirmam Bittencourt et al. (2012, p. 797), priorizado a "setores mais verdes"; (ii) abrir linhas de financiamento para iniciativas inspiradas no sistema de 
cascadas (projectos azuis); (iii) assegurar a assistência técnica, oferecida por um grupo de especialistas de acordo com a tipicidade da atividade. A assistência incluiria, por exemplo, o fluxo das matérias-primas e as formas de aproveitamento dos resíduos a gerar em suas atividades, o que alimentaria a economia circular e eficiência produtiva.

\subsection{Potenciar o paradigma verde e transitar ao paradigma azul}

O Índice Global de Economia Verde, que até 2016 media o desempenho de 80 países e 50 cidades do mundo em termos de progressos rumo à economia verde, coloca Moçambique numa posição global não confortável (49a posição ${ }^{13}$ ), o que implica haver problemas de sustentabilidade. Das 4 dimensões consideradas, o país tem melhorado apenas na dimensão Liderança e Mudanças Climáticas, ocupando a $5^{\text {a }}$ posição, o que revela que Moçambique tem forte liderança em torno da mudança climática e baixa intensidade de carbono (GGEI, 2016, p. 46). Contudo, ainda prevalecem desafios nas outras três dimensões. $\mathrm{Na}$ dimensão Mercados e Investimentos, Moçambique posiciona-se na 80a e última posição do ranking, revelando uma grande debilidade em investimentos para energias renováveis, tecnologias limpas e infra-estruturas verdes. $\mathrm{Na}$ dimensão Meio Ambiente, cujos indicadores incluem agricultura, qualidade do ar, águas, pesca, florestas, biodiversidade e habitat, o país está em torno da $60^{a}$ posição. Finalmente, na dimensão Setores de Eficiência, cujos indicadores abarcam construções, transporte, energia, turismo e uso eficiente de recursos, o país está posicionado em torno da média (40ª posição), indiciando igualmente fragilidades nestas áreas. Assim, Moçambique precisa aumentar investimento em energias renováveis, tecnologia limpa, nanotecnologia e em infra-estruturas verdes não somente para robustecer as dimensões do paradigma verde, mas também para viabilizar a transição ao paradigma azul.

\subsection{Formular políticas integradas e consistentes}

Para alcançar um desenvolvimento sustentável, várias políticas capazes de viabilizar as economias verde-azul precisam ser consideradas num único kit. Não se trata, contudo, de elaborar um documento único capaz de integrar todos os aspetos atinentes à sustentabilidade, mas de formular políticas setoriais tendo a sustentabilidade como princípio norteador. Uma política pública, por exemplo, que garanta sustentabilidade econômica, ambiental e social é, por sua natureza, complexa e exige integração de vários aspetos transversais que a tornem factível. Nestes termos, não se trata de elaborar uma política atinente à economia azul, mas, reconhecendo a transversalidade e grande interesse no pódio de desenvolvimento dos stakeholders (partes interessadas), deverá trespassar virtualmente por todas as políticas, como sejam, as do ambiente (umbrela), as de educação, as de habitação, as de economia (indústria), as da saúde, assim por diante. A sustentabilidade deveria ser o ponto de encontro de todas as políticas.

\subsection{Assumir o paradigma azul como modelo sustentável de desenvolvimento}

13 A situação piorou em 2018, em que o país ocupou 98a posição do universo de 130 países (GGEI, 2018). 
A questão da sustentabilidade não deve ser vista como uma meta estática, alcançável com políticas radicais, mas sim como ampliada e progressiva. A sustentabilidade é ampliada se conciliar "o encontro político entre a agenda ambiental e a agenda social, anunciando a necessidade de se enfrentar a degradação ambiental junto com o problema da pobreza". A sustentabilidade progressiva é vista como "um processo a ser construído paulatinamente e capaz de romper o círculo vicioso da produção excludente e implantar um círculo virtuoso" (Guerreiro et al., 2009, p. 3). Neste sentido, tem de haver um compromisso político para assumir o paradigma azul como uma plataforma de sustentabilidade, quer ampliada (proteger ambiente ao mesmo tempo que se combate a pobreza), quer progressiva (assegurar equidade e inclusão social através de oportunidades de emprego). Isto implica que o paradigma de desenvolvimento azul demanda "um governo capaz de integrar políticas ambientais com considerações econômicas" (Patil et al, 2016, p. 58).

Um efetivo compromisso político implicaria, também, que o governo possa atrair empreendedores, através de políticas e legislação favoráveis bem como a construção de infra-estruturas econômicas - particularmente as que suportam a produção de energias limpas -, a investir em determinadas áreas identificadas e que possam viabilizar a estratégia sugerida pelo modelo, designadamente, o agrupamento de atividades produtivas segundo o fluxo dos materiais para permitir uma economia circular e, dessa forma, se criar oportunidades de acrescentar valor à economia. No geral, para lidar com os desafios no âmbito de desenvolvimento sustentável, os atores precisam ter especial atenção ao paradigma azul em todas as suas ações de produção e consumo. Deve haver, sobretudo, um cometimento político e assumir o paradigma azul como plataforma sustentável de desenvolvimento a longo termo e agir para concretizá-lo, pois, como afirma Nhachengo (2014), a questão de desenvolvimento sustentável é, acima de tudo, uma questão de vontade política assim como de possibilidade econômica.

\section{Considerações Finais}

A degradação dos ecossistemas é um problema longínquo que vem conhecendo seu apogeu desde o século XVIII, com a efetivação da Revolução Industrial baseada em combustíveis fósseis. Este problema, com as vicissitudes que causa aos ecossistemas, é catalisado pela ambição do homem de maximizar os ganhos econômicos em detrimento dos benefícios ecológicos, recorrendo à exploração dos recursos acima da capacidade regenerativa dos ecossistemas e usando métodos ofensivos ao ambiente. Para erradicar o problema e garantir um futuro melhor para todos, há consenso da necessidade de promover um desenvolvimento sustentável, aquele que contemple a interdependência das dimensões ambiental, social e econômica, e que se mantenha pelos tempos como círculo virtuoso. Para potenciar o alcance de sustentabilidade vários modelos normativos têm vindo a serem propostos nos últimos 60 anos.

Este artigo visava fazer uma abordagem do desenvolvimento, analisando a essência das políticas dos paradigmas verde-azul como modelos de sustentabilidade. As políticas no âmbito do paradigma verde focam na dimensão econômica e ambiental e procuram 
concretizar uma transição progressiva da economia marron, de base fóssil, para economia verde, de baixo carbono e de maior eficiência energética. As políticas no âmbito do paradigma azul, por outro lado, complementam as estratégias do modelo verde focando em todas as dimensões da sustentabilidade e procuram concretizar uma transição da situação de escassez de recursos para a suficiência e, posteriormente, transitar desta suficiência para um cenário ideal de prosperidade geral, recorrendo a inovações, clustering de atividades produtivas e produção em sistemas de cascada, observado o constrangimento dos recursos disponíveis. $\mathrm{O}$ artigo constata que os paradigmas verde-azul, oferecendo uma gama flexível de alternativas operacionais, concorrem vigorosamente para moldar as políticas dos estados para se alcançar a sustentabilidade. Todavia, o paradigma azul constitui um particular quadro de referência que inspira a humanidade a transcender suas limitações para estabelecer visões sobre as possibilidades ilimitadas de desenvolvimento, através de instrumentos práticos e inovativos de formas de produção e consumo capazes de conduzir a sociedade à suficiência e à prosperidade global.

$\mathrm{O}$ estudo identificou fragilidades que prevalecem no âmbito do paradigma verde e desafios que se colocam no âmbito do azul. Entre os desafios que Moçambique precisa considerar para assegurar a sustentabilidade, destaca-se a educação ambiental através de canais formais e não formais; incentivo a iniciativas empreendedoras por intermédio de subsídios e incentivos fiscais, financiamento de projetos azuis e assegurar assistência técnica; investimento em infra-estruturas verdes e tecnologia limpa para viabilizar a transição ao paradigma azul; formular políticas com foco na sustentabilidade; e assumir o paradigma azul como modelo sustentável de desenvolvimento. É fundamental haver compromisso político para que, de forma progressiva e consoante as possibilidades reais do país, se possa concretizar esta visão global de desenvolvimento.

Artigo recebido em 10 de maio de 2021 e aprovado para publicação em 26 de julho de 2021

O presente trabalho foi realizado com apoio do Programa de Estudantes-Convênio de Pós-Graduação - PEC-PG, da CAPES-Brasil.

\section{Referências Bibliográficas}

AVALIAÇÃO ECOSSISTÊMICA DO MILÉNIO [MEA].Avaliação Ecossistêmica do Milénio. 2005. Disponível em www.millenniumassessment.org/en/index.html, acesso em 9 de Agosto de 2017.

BITTENCOURT, A. L.; Vieira, R. S. \& Martins, Q. J. N. Economia verde: conceito, críticas e instrumentos de transição. Revista Electrónica Direito e Política, Itajaí, v.7, n.2, 2012. Disponível em www.univali.br/direitoepolitica, acesso em 11 de Agosto de 2017.

BROWN, L. Plano B 4.0 - Mobilização para salvar a civilização. São Paulo: New Content Editora e Produtora, 2009.

BURKART, Karl. How do you define the 'green' economy? MNN - Mother Nature 
Network, 2009. Disponível em www.mnn.com/green-tech/research-innovations, acesso em 8 de Agosto de 2017.

CLIMATE TRANSPARENCY. Brown to Green: Assessing the G20 transition to a low-carbon economy. 2016. Disponível em www.climate-transparency.org/, acesso em 9 de Agosto de 2017.

CLIMATE TRANSPARENCY. Brown to Green: The G20 Transition Towards a Net-Zero Emissions Economy. 2019. Disponível em https://www.climate-transparency. org/g20-climate-performance/g20report2019, acesso em 20 de Abril de 2021.

ECONOMIST INTELLIGENCE UNIT.The Blue Economy: Growth, Opportunity and a Sustainable Ocean Economy. Briefing Paper for the World Ocean Summit 2015. Disponível em www.economistinsights.com/, acesso em 25 de Junho de 2017. ELLIOTT, Jennifer A. An Introduction to Sustainable Development, $3^{\text {rd }}$ edition, London \& New York: Routledge, 2006.

GLOBAL GREEN ECONOMY INDEX [GGEI]. Data from the 2018 Global Green Economy Index. Dual Citizen LLC, September 2018. Disponível em https:// dualcitizeninc.com/global-green-economy-index/, acesso em 3 de Julho de 2020.

GLOBAL GREEN ECONOMY INDEX [GGEI]. Measuring National Performance in the Green Economy. $5^{\text {th }}$ Edition, Dual Citizen LLC, September, 2016.

GOVERNO DE MOÇAMBIQUE [GdM]. Estratégia da Revolução Verde em Moçambique. Maputo: CIEDIMA, 2007.

GUERREIRO, E. P. et al. Desenvolvimento sustentável e governação participativa. Editora IWACP: São Paulo, 2009.

HUXLEY, Anne-Maree. Australian Blue Paper No 1. NEE McInerney, October 2015.

MARGULIS, Lynn \& KARLENE, V. Schwartz. Five Kingdoms. $1^{\text {st }}$ edition, New York: W.H. Freeman, 1982.

NHACHENGO, R. Models to Improve the Living Conditions of Squatter Dwellers and Slum Inhabitants of Maputo City. 2014. Dissertação submetida a Jindal School of Government and Public Policy, Haryana: JGU, 2014.

OECD. Green Growth Indicators 2014. Paris: OECD, 2013.

OECD. The Ocean Economy in 2030. Paris: OECD, 2016.

OECD. The Well-Being of Nations: The Role of Human and Social Capital. Paris: OECD, 2001.

OECD. Towards Green Growth: a Summary for Policy Makers. Paris: OECD, 2011.

PATIL, P.G. et al. Toward a Blue Economy: a Promise for Sustainable Growth in the Caribbean. Washington D.C.: The World Bank, 2016.

PAULI, G. (s/d), The blue economy. Disponível em www.theblueeconomy.org/thebook.html, acesso em 21 de Agosto de 2017 e 3 de Julho de 2020.

PAULI, Gunter. From Deep Ecology to The Blue Economy. ZERI, February 2011. ROGERS, Peter P., Kazi F. Jalal \& John A. Boyd. An introduction to sustainable 
development. UK and USA: Earthscan, 2008.

UNDP. Transforming our world: the 2030 Agenda for Sustainable Development. 2015. Disponível em https://sustainabledevelopment.un.org, acesso em 9 de Agosto de 2017.

UNEP et al. Green Economy in a Blue World. 2012. Disponível em www.unep.org/ greeneconomy, acesso em 9 de Agosto de 2017.

UNITED NATIONS (UN). The Future We Want. Rio de Janeiro: UNCSD, 2012. UNITED NATIONS (UN). The Rio Declaration on Environment and Development. Rio de Janeiro: UNCED, 1992.

WALKER, Kris. What is Green Nanotechnology? 2013. Disponível em www. azocleantech.com/article.aspx?ArticleID=330, acesso em 22 de Agosto de 2017.

WWF (s/d). Principles for a Sustainable Blue Economy. Disponível em www. panda.org/baltic, acesso em 23 de Agosto de 2017.

YADONG, Y. et al. Eco-efficiency trends in china, 1978-2010: decoupling environmental pressure from economic growth. Ecological Indicators, n. 24, 2013, pp. 177-184.

ZERO EMISSIONS RESEARCH AND INITIATIVES [ZERI]. ZERI 20 Years. Disponível em http://www.zeri.org/ZERI/Home.html, acesso em 23 de Agosto de 2017. 